\title{
EFFECT OF ADDING RAPESEED OIL, FISH OIL AND SELENIUM ON THE DIET ENRICHED WITH VITAMIN E AND ZINC ON THE YIELD AND ORGANOLEPTIC PROPERTIES OF EGGS
}

\author{
Yadollah BAHRAMI ${ }^{1 \times}$, Elham REZVANNEJAD² and Farhan AHADI ${ }^{3}$ \\ 1PhD of Animal Biotechnology, Young Researchers Elite Club, Isfahan (Khorasgan) Branch, Islamic Azad University, Isfahan, Iran \\ 2PhD, Department of Biotechnology, Institute of Science and High Technology and Environmental Sciences, Graduate University of \\ Advanced Technology, Kerman, Iran \\ 3DVM, Department of Animal Science, Islamic Azad University, Marageh Branch, Marageh, Iran
}

Email: bahrami97@gmail.com; (DORCiD: 0000-0002-9816-9685

supporting Information

\begin{abstract}
The present study was investigated the simultaneous effect of fish oil and rapeseed, selenium, vitamin $E$ and zinc supplementation on laying hens. 288 white-line layers were used from 45 weeks of age. The experiment was conducted using a completely randomized design with four replications for 75 to 90 days. Performance of hens and organoleptic properties of eggs were evaluated. The results showed that there was no any significant difference between groups on the yield. Results obtained from the tasters including overall taste, natural smell and overall acceptability showed that although increasing fish oil to $2 \%+2 \%$ rapeseed oil did not have a significant effect on the overall taste and overall acceptability of eggs in this group, but were significantly reported in natural smell. Therefore, diet with $2 \%$ fish oil+2\% rapeseed oil (T3) can be considered as an enriched omega-3 ratio without showing major quality drop in eggs acceptance.
\end{abstract}

Keywords: Egg taste, Fish oil, Laying hen, Quality of egg, Rapeseed oil

\section{INTRODUCTION}

What is always about egg in mind is its nutritional value, but eggs also have other important effects that make this valuable protein component separate from other foods. Eggs are a good source of necessary protein, vitamins and minerals, and can be an important nutrient in the diet of individuals (Bourre and Galea, 2006). Simopoulos and Salem (1989) showed that in Greece, hens that were allowed to feed freely, especially those fed with weed and ALA-rich grains, had a good growth, and their eggs had more omega-3 fatty acids than other hens grown in cage. Wild birds also had eggs with more concentrations of omega-3 fatty acids (Leskanich and Noble, 2007).

Food sources of omega-3 fatty acids can be divided into two categories of plant and animal products. Plant sources of this type of fatty acids contain high level of LNA, but other levels of omega-3 fatty acids are low in these categories of food sources. Among the plants that contain these fatty acids are fennel, walnut, soya, canola oil, and some green plants such as some algae (Kumar et al., 2016). Animal sources of these fatty acids contain high levels of EPA and DHA fatty acids and low levels of LNA. Among the animal resources, fish are rich in these types of fatty acids (Thng et al., 2020; Chekaniazar and Shahryar, 2018). Therefore, eggs fed with certain amounts of fish oil are also a source of nutrients for omega-3 fatty acids for humans. Using a proper combination of vegetable oils and fish oil can provide good results in increasing the amount of omega-3 fatty acids in egg yolk.

Researchers have reported that omega-3 fatty acids are more unsaturated type and longer chains of unsaturated fatty acids with multiple double bond (LC n-3 PUFA) such as Eicosapentaenoic (EPA), Ducosapentaenoic (DPA) and Docosahexaenoic (DHA), which causes to upgrade the power of the immune system (Molfino et al., 2014). AlphaLinolenicacid (LNA) has little metabolic activity or not at allused until it is converted to DHA (Molfino et al., 2014).

The use of omega-3 fatty acids in vegetable or sea oils, along with appropriate levels of vitamins, especially vitamins $A$ and $E$, in poultry diets, has a significant effect on health improvement, increasing performance and in particular increasing the deposition of omega-3 fatty acids long chain in the meat. It also increases concentration of lipid (fat)soluble vitamins (Beynen, 2004; Galea, 2003). Finally, by consuming omega-3 product by human communities, reducing cardiovascular diseases, improving health and increasing human life is possible (Bourre, 2005). Enrichment of animal products such as bird meats, eggs, milk, etc., in addition to proper meet of nutritional deficiencies, is being carried out to increase the amount of important material needed for body to increase the health or reduce the disease by improving the 
immune system (Bourre, 2005). Among the essential nutrients of the body, unsaturated fatty acids such as omega-3 as well as some vitamins and minerals such as vitamin $\mathrm{E}$ and selenium are very important in the diet (Fisinin et al., 2008).

Hulan et al. (1988) by adding $5 \%$ of fish powder to the diet of laying hens found that total amounts of omega-3, EPA, DPA, and DHA fatty acids were significantly increased in carcass. Feeding of hens with 0, 4, 8 and $12 \%$ of fish powder did not have an effect on mortality, feed consumption efficiency and body weight, but by increasing levels of fish powder in the diet, the amounts of EPA, DHA and omega-3 fatty acids in eggs were increased. Also, all treatments increased the amount of omega-3 fatty acids in breast meat. In general, the addition of fish oil increases the ratio of omega-3 to omega6 in total tissues (Hulan et al., 1988). Ebeid (2011) reported that increasing omega-3 levels of the diet plays a protective role against coccidiosis factor in birds.

Thus, due to the existence of different amounts of unsaturated fatty acids in vegetable and animal oils, and since so far, the simultaneous use of different amounts of fish oil and rapeseed oil in the diet has not been investigated on the quality of eggs in laying hens. The present study was designed to evaluate and compare the different amounts of this compound in the diet of laying hens.

\section{MATERIALS AND METHODS}

A total of $\mathbf{2 8 8}$ laying hens at the laying eggs peak were used in the poultry farm of Islamic Azad University. Diets included fish oil and rapeseed oil with a level of $4 \%$ combined with organic selenium (Selplex Organic Selenium Formation from Saccharomyces cerevisiae) and the same levels of organic zinc (Bioplex- $\mathrm{Zn}$ ) and vitamin $\mathrm{E}$ and formulated according to NRC's recommendations (Council, 1994) with a uniform energy, protein, fiber, amino acids and minerals (Table 1). The experiment was conducted using a completely randomized CRD-based design (4 treatments, each with four iterations) for 75 to 90 days.

\section{Table 1 - Components and compositions of control and experimental diets}

\begin{tabular}{|c|c|c|}
\hline Food components & Treatment * & Control \\
\hline Corn grain & 40.00 & 50.50 \\
\hline Soybean Meal & 21.75 & 22.5 \\
\hline Wheat & 24.50 & 11.00 \\
\hline Starch & 0.00 & 6.00 \\
\hline Oil additives 1 & 4.00 & 0.00 \\
\hline Oyster Powder & 8.00 & 8.00 \\
\hline powder of bone & 1.35 & 1.20 \\
\hline DDL-Methionine & 0.20 & 0.10 \\
\hline Salt & 0.20 & 0.20 \\
\hline Vitamin supplement 2 & $0.25 *$ & 0.25 \\
\hline Mineral supplement 3 & $0.25 *$ & 0.25 \\
\hline \multicolumn{3}{|c|}{ Calculated nutrient compositions (on dry matter) } \\
\hline Metabolism energy (kcal / kg) & 2869 & 2813 \\
\hline Crude protein (\%) & 15.78 & 15.55 \\
\hline Crude fiber (\%) & 3.15 & 3.28 \\
\hline Crude fat $(\%)$ & 5.25 & 2.43 \\
\hline Calcium (\%) & 3.40 & 3.34 \\
\hline Available phosphorus (\%) & 0.33 & 0.33 \\
\hline Lysine (\%) & 0.85 & 0.80 \\
\hline \multicolumn{3}{|c|}{ 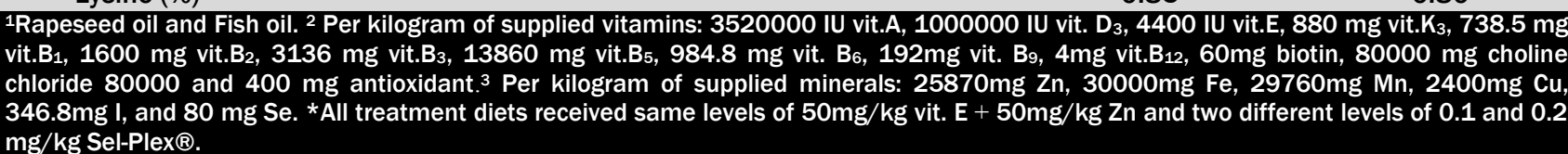 } \\
\hline
\end{tabular}

\section{Performance}

The performance traits including egg weight, daily feed intake, feed efficiency and egg percentage were determined during the experiment. Feed intake was measured every two weeks, and on the last day (end of each period) the remaining food was collected from each unit and the total diet was deducted. Then, by dividing the amount of feed consumed by that unit of test, each hen's feed intake per day of the same unit of experiment was obtained.

\section{Organoleptic quality}

Organoleptic test is performed using peers and a single sex to provide the best oil, alone or in combination, in terms of acceptable smell and taste for human nutrition. An educated and volunteer specialist (with conditions between 20 and 50 years old, without sensitivity to the hens and its products, a permanent consumer of eggs at least once a week) was used for this organoleptic evaluation. The eggs were boiled and evaluated in water at the same time and at a set temperature. The maximum score from 10 to at least $\mathbf{2}$ for an appreciable trait such as taste, smell and a general result (acceptability) was assigned and results evaluated. 


\section{Statistical analysis}

The gathered data were analyzed after the normalization test using SAS 9.1 software and comparison of means was done using Duncan's multiple tests. The statistical model of the plan is as follows: $y_{i j}=\mu+t_{i}+e_{i j}$. Where, $y_{i j}=$ observed values of each dependent variable; $\mu=$ Overall mean; $t_{i}=E f f e c t$ of treatment; $e_{i j}=$ Random error

\section{Ethical approval}

The research and ethics committee in the Department of Animal Science of Isfahan (Khorasgan) Branch of Islamic Azad University approved this study based on international welfare standards for use of animals in conducting research.

\section{RESULTS and DISCUSSION}

\section{Performance}

There was no any significant difference between treatments and control groups on performance traits (Table 1). Same results were reported by Meluzzi et al. (2000) who used different oils for enrichment of laying hen eggs (fish oil and fat at $3 \%$ level with different levels of vitamin E), and also Dalle Zotte et al. (2015) feeding the laying hens in a diet containing $3 \%$ fatty fish oil. These results are also consistent with a study by Al-Sultan (2005), which showed no change in the production of eggs. However, Novak and Scheideler (2001) reported that feed intake for hens fed $10 \%$ flaxseed oil diet was significantly higher than those received soya oil diets $(P<0.05)$. Dong et al. $(2018)$ reported that hens fed fish oil showed poor performance compared with soybean oil or coconut oil, and especially egg weight was significantly decreased due to dietary fish oil.

An examination of the results of egg quality tests including overall taste, natural smell and overall acceptability showed that although increasing fish oil to $2 \%$ with $2 \%$ rapeseed did not have a significant effect on the overall taste and overall acceptability of eggs in this group, but were significantly reported in natural smell by the panelists (Table 2 ). The eggs of treatment 2 followed by treatment 1 (1\% of fish oil $+3 \%$ of rapeseed oil) with the highest score of natural smell were accepted by the panelists. This means that the existence of more fish oil can change the smell of the enriched product, although it contains a much higher amount of vitamins and omega-3 fatty acids and elements. Generally, by study the results of the overall acceptability and taste of the tested samples, the consumption of the eggs of treatment 3 and 4, which contained the same amounts of both fish oil and rapeseed, seems very suitable in among of the level of enrichment of this product. Galobart et al. (2001) and Qi and Sim (1998) did not observed any significant effects on egg quality and performance in similar studies. (Brelaz et al., 2019) by using eight treatments diets with fish waste oil (0, 0.5 , 1.0, 1.5, 2.0, 2.5, 3.0 and 3.5\%) found and increased percentage of feed intake until $2.5 \%$ of fish waste oil in some of diets. They also were observed significant differences in flavor. Eggs from birds fed diets up to $2 \%$ present better acceptance by the tasters, while for higher levels of fish waste oil there was a considerable drop in acceptance.

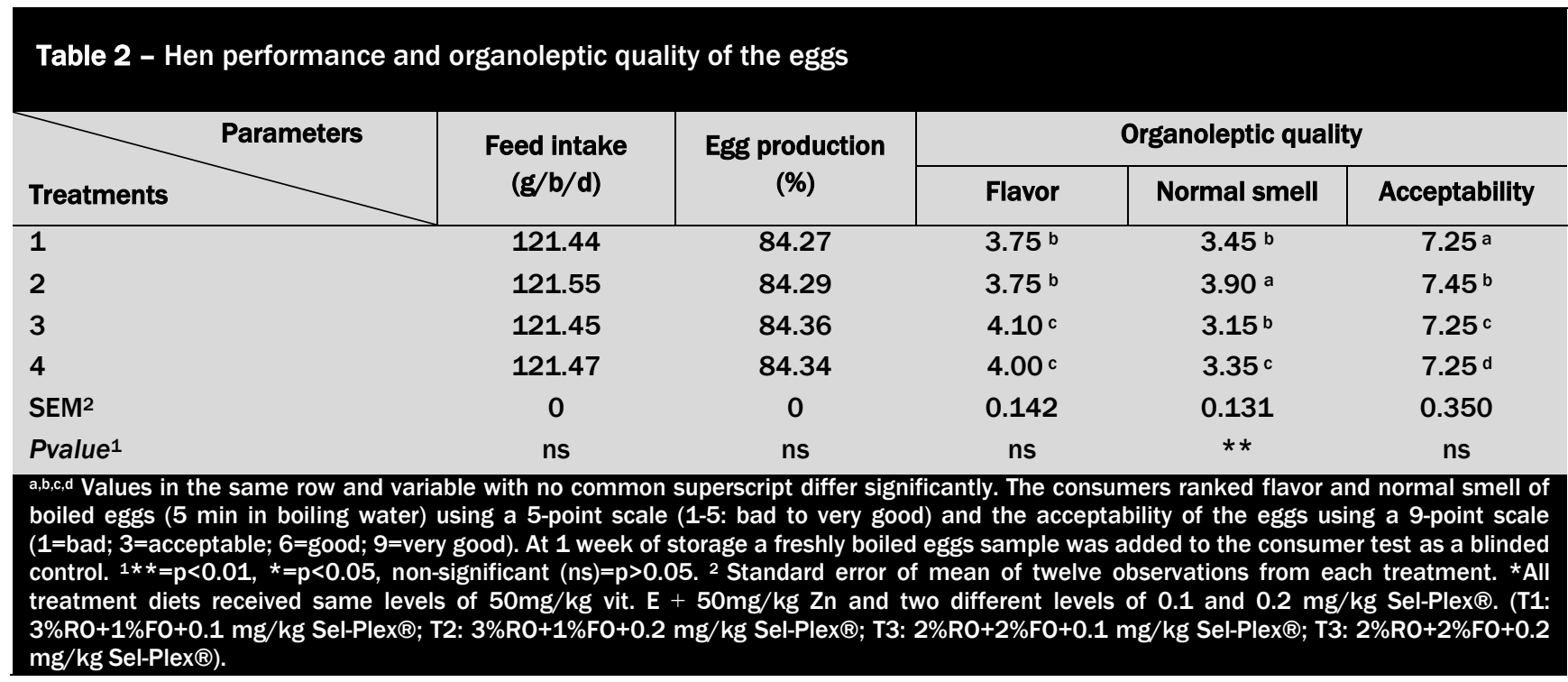

\section{CONCLUSION}

Results of this study showed that using 0.1 and $0.2 \mathrm{mg} / \mathrm{kg}$ organic selenium levels with the same levels of vitamin $\mathrm{E}$ and organic zinc in diets containing rich fatty acids (omega-3 and -6) and also combining fish oil with a rich plant source from omega-3 (rapeseed oil), the transmission of fish smell to eggs can be reduced. Therefore, using a $2 \%$ omega-3 oil (fish) + 
$2 \%$ omega-6 oil (rapeseed) can be considered as a good ratio of omega-3 without making major quality drop in eggs acceptance.

\section{DECLARATIONS}

Corresponding Author

E-mail: bahrami97@gmail.com

\section{Acknowledgements}

Financial support of Young Researchers Elite Club, Isfahan (Khorasgan) Branch, Islamic Azad University, Isfahan, Iran, is highly acknowledged.

\section{Authors' Contribution}

Both authors contributed equally in this manuscript.

\section{Conflict of interests}

The authors have not declared any conflict of interests.

\section{REFERENCES}

Al-Sultan S (2005). Effect of dietary fish oil on production traits and lipid composition of laying hens. International Journal of Poultry Science 4(8): 586-588. Google Scholar

Beynen FBA (2004). Relationships between the intake of $n-3$ polyunsaturated fatty acids by hens and the fatty acid composition of their eggs. International Journal of Poultry Science 3(11): 690-696. Google Scholar

Bourre JM (2005). Where to find omega-3 fatty acids and how feeding animals with diet enriched in omega-3 fatty acids to increase nutritional value of derived products for human: what is actually useful ? The journal of nutrition, health \& aging 9(4): 232-242. Google Scholar

Bourre JM and Galea F (2006). An important source of omega-3 fatty acids, vitamins D and E, carotenoids, iodine and selenium: a new natural multi-enriched egg. The journal of nutrition, health \& aging 10(5): 371-376. Google Scholar

Brelaz K, Cruz F, Brasil R, Silva A, Rufino J, Costa V and Viana Filho G (2019). Fish Waste Oil in Laying Hens* Diets. Brazilian Journal of Poultry Science 21(4). http://dx.doi.org/10.1590/1806-9061-2019-1069 I Google Scholar

Chekaniazar S and Shahryar HA (2018). Omega-3 enrichment of broiler dark meat: reducing unlike fats and fishy taint for consumer acceptance. Online Journal of Animal and Feed Research 8(3): 74-83. Google Scholar

Council NR (1994). Nutrient Requirements of Poultry, National Academy Press. Washington, DC. Google Scholar

Dalle Zotte A, I A, V G and Marchesini G (2015). Dietary enrichment of n-3 PUFA for laying hens: Effect of different sources on production, composition and quality of eggs. Google Scholar

Dong XF, Liu S and Tong JM (2018). Comparative Effect of Dietary Soybean Oil, Fish Oil, and Coconut Oil on Performance, Egg Quality and Some Blood Parameters in Laying Hens. Poultry Science 97(7): 2460-2472. https://doi.org/10.3382/ps/pey094 I Google Scholar

Ebeid TA (2011). The impact of incorporation of $n-3$ fatty acids into eggs on ovarian follicular development, immune response, antioxidative status and tibial bone characteristics in aged laying hens. animal 5(10): $1554-1562$. https://doi.org/10.1017/S1751731111000619 I Google Scholar

Fisinin V, Papazyan T and Surai P (2008). Producing specialist poultry products to meet human nutrition requirements: Selenium enriched eggs. World's poultry science journal $64(1)$ : 85-98. https://doi.org/10.1017/S0043933907001742 I Google Scholar

Galea F, Bourdillon, A., Rouillère, H. (2003). Effect of different levels and sources of omega-3 fatty acids in diets for laying hens on eggs acid profile. Scientific Report of the 24th ISF World Congress. Google Scholar

Galobart J, Barroeta AC, Baucells MD, Cortinas L and Guardiola F (2001). Alpha-tocopherol transfer efficiency and lipid oxidation in fresh and spray-dried eggs enriched with omega3-polyunsaturated fatty acids. Poultry science 80(10): 1496-1505. https://doi.org/10.1093/ps/80.10.1496 I Google Scholar

Hulan HW, Proudfoot FG, Ackman RG and Ratnayake WMN (1988). Omega-3 Fatty Acid levels and performance of broiler chickens fed Redfish meal or Redfish oil. Canadian Journal of Animal Science 68(2): 533-547. https://doi.org/10.4141/cjas88-059 I Google Scholar

Kumar A, Sharma A and Upadhyaya KC (2016). Vegetable Oil: Nutritional and Industrial Perspective. Current genomics 17(3): 230-240. Google Scholar

Leskanich CO and Noble RC (2007). Manipulation of the n-3 polyunsaturated fatty acid composition of avian eggs and meat. World's Poultry Science Journal 53(2): 155-183. https://doi.org/10.1079/WPS19970015 I Google Scholar

Meluzzi A, Sirri F, Manfreda G, Tallarico N and Franchini A (2000). Effects of dietary vitamin E on the quality of table eggs enriched with n-3 long-chain fatty acids. Poultry science 79(4): 539-545. https://doi.org/10.1093/ps/79.4.539 I Google Scholar

Molfino A, Gioia G, Rossi Fanelli F and Muscaritoli M (2014). The role for dietary omega-3 fatty acids supplementation in older adults. Nutrients 6(10): 4058-4073. https://doi.org/10.3390/nu6104058 I Google Scholar 
Novak C and Scheideler SE (2001). Long-Term Effects of Feeding Flaxseed-Based Diets. 1. Egg Production Parameters, Components, and Eggshell Quality in Two Strains of Laying Hens1. Poultry science 80(10): 1480-1489. https://doi.org/10.1093/ps/80.10.1480 I Google Scholar

Qi G-H and Sim JS (1998). Natural Tocopherol Enrichment and Its Effect in n-3 Fatty Acid Modified Chicken Eggs. Journal of Agricultural and Food Chemistry 46(5): 1920-1926. https://doi.org/10.1021/if9707804 I Google Scholar

Simopoulos AP and Salem N, Jr. (1989). n-3 fatty acids in eggs from range-fed Greek chickens. The New England journal of medicine 321(20): 1412. https://doi.org/10.1056/nejm198911163212013 I Google Scholar

Thng A, Ting JX, Tay HR, Soh CY, Ong HC and Tey D (2020). The use of predicted apparent metabolizable energy values to understand the oil and fat variability in broilers. Online Journal of Animal and Feed Research 10(4): 85-92. Google Scholar 